\title{
Estrogen stimulates microglia and brain recovery from hypoxia-ischemia in normoglycemic but not diabetic female mice
}

\author{
Liqun Zhang, ${ }^{1,2}$ Aji Nair, ${ }^{2}$ Kyle Krady, ${ }^{2}$ Christopher Corpe, ${ }^{2}$ Robert H. Bonneau, ${ }^{3}$ \\ Ian A. Simpson, ${ }^{2}$ and Susan J. Vannucci ${ }^{4}$ \\ ${ }^{1}$ Department of Pediatrics, \\ ${ }^{2}$ Department of Neural and Behavioral Sciences, and \\ ${ }^{3}$ Department of Microbiology and Immunology, Milton S. Hershey Medical Center/Pennsylvania State University \\ College of Medicine, Hershey, Pennsylvania, USA \\ ${ }^{4}$ Department of Pediatrics, Division of Critical Care Medicine, Morgan Stanley Children's Hospital of New York, \\ Columbia University College of Physicians and Surgeons, New York, New York, USA
}

\begin{abstract}
Diabetic hyperglycemia increases ischemic brain damage in experimental animals and humans. The mechanisms are unclear but may involve enhanced apoptosis in penumbral regions. Estrogen is an established neuroprotectant in experimental stroke. Our previous study demonstrated that female diabetic $d b / d b$ mice suffered less damage following cerebral hypoxia-ischemia (H/I) than male $d b / d b$ mice. Here we investigated the effects of diabetes and estrogen apoptotic gene expression following $\mathrm{H} / \mathrm{I}$. Female $d b / d b$ and nondiabetic (+/?) mice were ovariectomized (OVX) and treated with estrogen or vehicle prior to $\mathrm{H} / \mathrm{I}$; brains were analyzed for damage and $b c l-2$ family gene expression. OVX increased ischemic damage in $+/$ ? mice; estrogen reduced tissue injury and enhanced antiapoptotic gene expression ( $b c l-2$ and $b f l-1) . d b / d b$ mice demonstrated more damage, without increased $b c l-2$ mRNA; $b f l-1$ expression appeared at 48 hours of recovery associated with infarction. To our knowledge, this is the first description of $b f l-1$ in the brain with localization to microglia and macrophages. Early induction of $b f l-1$ expression in $+/ ?$ mouse brain was associated with microglia; delayed $b f l-1$ expression in diabetic brain was in macrophages bordering the infarct. Furthermore, estrogen replacement stimulated early postischemic expression of $b c l-2$ and $b f l-1$ and reduced damage in normoglycemic animals but failed to protect the diabetic brain.
\end{abstract}

J. Clin. Invest. 113:85-95 (2004). doi:10.1172/JCI200418336.

\section{Introduction}

Diabetes is a recognized risk factor for stroke and frequently enhances tissue damage once an ischemic insult has begun. Diabetic stroke patients have increased mortality and prolonged recovery time relative to nondiabetics (1). Postmenopausal diabetic women represent a specific at-risk group with a greater incidence of stroke as compared with age-matched men or nondiabetic women $(2,3)$. It has been suggested that the loss of female reproductive steroids in some manner potentiates the neurologic complications of diabetes; however, there are no studies to either support or refute a unique pathophysiology of stroke in diabetic women.

Received for publication March 12, 2003, and accepted in revised form November 4, 2003.

Address correspondence to: Susan J. Vannucci, Department of Pediatrics, Division of Critical Care Medicine, Morgan Stanley Children's Hospital of New York, Columbia University College of Physicians and Surgeons, 3959 Broadway, BHN 10-24, New York, New York 10032, USA. Phone: (212) 305-8458;

Fax: (212) 342-2293; E-mail: sv2020@columbia.edu.

Conflict of interest: The authors have declared that no conflict of interest exists.

Nonstandard abbreviations used: hypoxia-ischemia (H/I); cerebral blood flow (CBF); ovariectomized (OVX); $17-\beta$ estradiol (E); RNase protection assay (RPA); glial fibrillary acidic protein (GFAP); middle cerebral artery occlusion (MCAO).
We previously examined the impact of diabetes and gender on cerebral metabolism and tissue damage following cerebral hypoxia-ischemia (H/I) in a genetic model of type 2 diabetes, the $d b / d b$ mouse (4). The $d b / d b$ mouse has a point mutation in the gene for the leptin receptor, resulting in a truncated, nonfunctional protein $(5,6)$ that produces a phenotype of diabetic hyperinsulinemia and hyperglycemia (7). Diabetic hyperglycemia exacerbates mortality and ischemic brain damage in both male and female mice; the females exhibit smaller infarcts than their male counterparts, indicating a neuroprotective effect of estrogen in diabetic as well as control mice (4).

The neuroprotective effects of estrogen in experimental models of stroke are complex and involve both vascular and nonvascular effects (for review see Hurn and Macrae [ref. 8]). Our previous study demonstrated that end-ischemic cerebral blood flow (CBF) was not different between male and female diabetic mice (4). Therefore, in the present study, we focused on one of the several established nonvascular mechanisms of estrogen action, specifically a reduction in delayed cell death by bcl-2-mediated antiapoptotic activity $(9,10)$. Since it has long been suggested that diabetes increases the extent of ischemic damage by converting selective neuronal death in the penumbra into infarction 
(11-13), we hypothesized that increased apoptosis contributes to infarct expansion in diabetes and that female diabetic mice may be protected in part via a bcl-2mediated antiapoptotic mechanism.

The purpose of this study was to examine the effects of exogenously administered estrogen on the expression of $b c l-2$ and its family members following cerebral $\mathrm{H} / \mathrm{I}$ in female $d b / d b$ mice. Estradiol increased $b c l-2$ expression, and decreased damage, in nondiabetic $+/$ ? female mice; however, there were no comparable responses in the diabetics. In addition, we observed the induction of a novel antiapoptotic member of the $b c l-2$ family, $b f-1$, in microglia and macrophages in postischemic brains of both $+/$ ? and $d b / d b$ mice. Bfl- 1 expression in brains of normoglycemic mice was induced early in reperfusion (8-24 hours), was stimulated by estradiol treatment, and was localized to microglia. In contrast, $b f l-1$ was not induced in the diabetic brains until 48 hours of reperfusion, was not affected by estradiol treatment, and was localized to cells surrounding the largely infarcted tissue, primarily macrophages. We propose that the early microglial response following cerebral ischemia is neuroprotective and suggests another mechanism for estrogen action. In addition, failure to elicit this response in the diabetic may contribute to the exacerbation of brain damage.

\section{Methods}

Animals. Female C57BL/KsJ $d b / d b$ mice and nondiabetic littermates (+/?) were purchased from The Jackson Laboratory (Bar Harbor, Maine, USA) at 4 weeks of age. To avoid hormonal variations due to the estrus cycle, all mice were subjected to bilateral ovariectomy (OVX) (14) at 5 weeks of age. One week later, mice received $5 \mu \mathrm{g}$ $17-\beta$ estradiol (E) (Sigma-Aldrich, St. Louis, Missouri, USA) in $0.1 \mathrm{ml}$ sesame oil (Sigma-Aldrich) intraperitoneally for a period of 12 days; controls received an equal volume of vehicle. Plasma estradiol levels were determined by RIA (DSL-39100; Diagnostic Systems Laboratories Inc., Webster, Texas, USA). At 8 weeks of age, animals were subjected to unilateral cerebral $\mathrm{H} / \mathrm{I}$ $\left(8 \% \mathrm{O}_{2}\right.$ /balance $\mathrm{N}_{2}, 20$ minutes, $36.5^{\circ} \mathrm{C}$ ) as previously described (4). Briefly, animals were anesthetized with halothane ( $4 \%$ in $70 \% \mathrm{~N}_{2} \mathrm{O}: 30 \% \mathrm{O}_{2}$ ), and a small incision was made in the neck. The right carotid artery was exposed and double-ligated with 4-O surgical silk, the incision was sutured, and the animals were allowed to recover with access to food and water for 3 hours. Systemic hypoxia was induced by exposure to $8 \% \mathrm{O}_{2} /$ balance $\mathrm{N}_{2}$ in temperature-controlled glass chambers $\left(35.5^{\circ} \mathrm{C}\right)$. At the end of the 20 -minute hypoxic interval, animals were allowed to recover and returned to their cages with free access to food and water, supplemented with $5 \%$ (wt/vol) glucose. The combination of unilateral carotid artery ligation with systemic hypoxia produces ischemia (50-60\% reduction in normal CBF) in the hemisphere ipsilateral to the ligation. Because CBF is restored to normal upon return to normoxic conditions, this is a model of transient unilateral cerebral ischemia, which produces reproducible brain damage in the ipsilateral, but not the contralateral, hemisphere (4).

At specific intervals of recovery from $\mathrm{H} / \mathrm{I}$ (i.e., reperfusion following return to normoxia), animals were sacrificed and brains were removed and cut coronally into four $2-\mathrm{mm}$ sections. These sections were frozen in isopentane $\left(-40^{\circ} \mathrm{C}\right)$, and $16-\mu \mathrm{m}$ cryosections were cut from each side for histology and in situ hybridization studies. To determine infarct fraction, cryosections were stained with $\mathrm{H} \& \mathrm{E}$, and hemispheric and infarct areas were analyzed with the NIH Image 1.64 image-analysis program. Infarct fraction was calculated as the percentage of the ratio of the damaged area to the area of the total hemisphere with correction for hemispheric swelling due to edema, as previously described (4): infarction $(\%)=([$ damaged area $/(1+[$ total ipsilateral area - contralateral area]/contralateral area)]/ contralateral area) $\times 100$. Temporal-parietal cortex, striatum, and hippocampus (ipsilateral and contralateral) were dissected from the remaining tissue for RNA isolation and analysis. All animal protocols were approved by the Pennsylvania State University College of Medicine Institutional Animal Care and Use Committee.
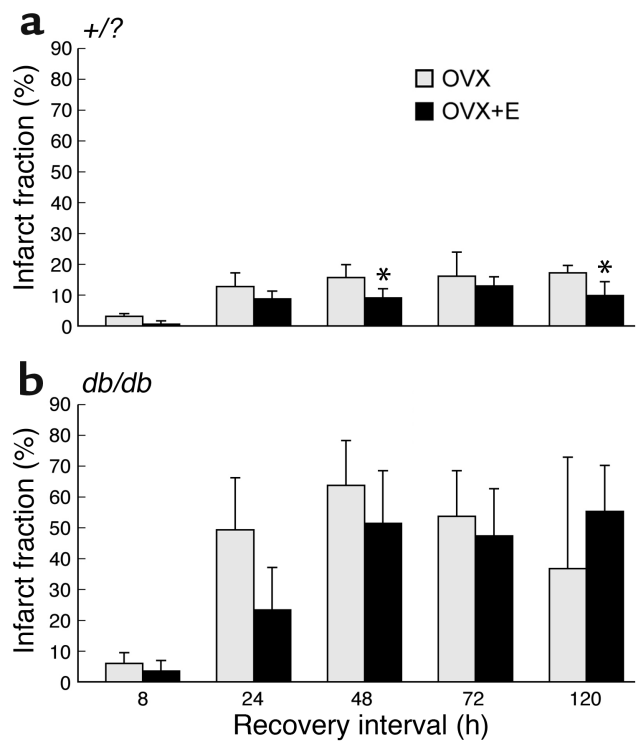

Figure 1

Evolution of hypoxic-ischemic damage in $+/$ ? and $d b / d b$ mice: effect of estrogen. Female $+/$ ? and $d b / d b$ mice were subjected to bilateral ovariectomy at 5 weeks of age and received $5 \mu \mathrm{g}$ estradiol intraperitoneally in sesame oil $(\mathrm{OVX}+\mathrm{E})$, or $5 \mu \mathrm{g}$ vehicle $(\mathrm{OVX})$, daily for 12 days prior to $\mathrm{H} / \mathrm{I}$. All mice were subjected to unilateral $\mathrm{H} / \mathrm{I}$ for 20 minutes as described in Methods and sacrificed at recovery intervals from 8 hours to 120 hours ( 5 days). Four 2-mm brain sections were frozen and $16-\mu \mathrm{m}$ cryosections were cut before isolation of RNA for subsequent analysis (Figures 2-4). Sections were stained with $\mathrm{H} \& \mathrm{E}$, and infarct fraction was calculated as a percentage of the contralateral hemisphere, as described in Methods. Bars represent mean infarct fraction \pm SD for four to six mice per group for nondiabetic $+/$ ? (a) and $d b / d b(\mathbf{b})$. *Significant effect of estrogen replacement, $P<0.05$. Values for $d b / d b \mathrm{OVX}+\mathrm{E}$ at 48 hours to 5 days were not different from one another and, when combined, were significantly greater than values at 24 hours $(P<0.05)$. 
In vitro studies of $B V-2$ cells. BV-2 cells are an established microglial cell line originally obtained from the laboratory of Virginia Bocchini (University of Perugia, Perugia, Italy). BV-2 cells were plated on $30-\mathrm{mm}$ tissue culture dishes and grown in $0.5 \%$ serum type M-CDM media for 24 hours. Media were then changed to serumfree, low-insulin ( $5 \mathrm{ng} / \mathrm{ml}$ ) M-CDM, and cells were maintained in a quiescent state for 48 hours. Half of the cells were activated with LPS $(500 \mathrm{ng} / \mathrm{ml}$; Escherichia coli serotype 055:B5; Sigma-Aldrich) for 6 hours.

RNase protection assays. Total RNA was isolated from frozen tissue or cells using TRI reagent (Molecular Research Center Inc., Cincinnati, Ohio, USA), according to the manufacturer's instructions. RNase protection assays (RPAs) for $b c l-W, b f l-1, b c l-X, b a k, b a x, b c l-2$, and bad were performed (RiboQuant mAPO-2; PharMingen, San Diego, California, USA). Purified samples were separated using a $6 \%$ urea-PAGE sequencing gel, and the fragments were visualized by phosphorimage analysis and quantitated using ImageQuant software (Molecular Dynamics, Sunnyvale, California, USA). Gene expression was normalized to the respective levels of GAPDH mRNA.

In situ bybridization and immunobistochemical studies. A 663-bp mouse bfl-1 cDNA probe (15) was cloned by PCR from a mouse kidney library using primers $5^{\prime}$-TTCCAACAGCCTCCAGATATGATTAGGG and $5^{\prime}$-CGTGGGAGCCAAGGTTCTCTCTGGTCCG. This probe was used to generate ${ }^{35}$ S-labeled riboprobes for in situ hybridization as previously described (16). ${ }^{35}$ S-labeled riboprobes for
IGF-1 were synthesized from a linearized plasmid containing a partial cDNA insert to rat IGF-1 (17). Following the initial autoradiographic exposure, cell-specific expression was analyzed by immunohistochemistry (18) with mouse monoclonal glial fibrillary acidic protein (GFAP) for astrocytes or neuron-specific TG2 antibody (provided by Steven Levison, Penn State Milton S. Hershey Medical Center, Hershey, Pennsylvania, USA, and Peter Davies, Albert Einstein Medical College, New York, New York, USA, respectively) using the ABC Elite kit (Vector Laboratories Inc., Burlingame, California, USA) with diaminobenzidine (Sigma-Aldrich). Lectin staining was performed using GSA I-B 4 Griffonia lectin (SigmaAldrich) as previously described (19). All sections were then dried, dipped in Kodak NTB-3 photographic emulsion (Eastman Kodak Co. Scientific Imaging Systems, New Haven, Connecticut, USA), developed, and counterstained with hematoxylin. Double immunofluorescence was performed using a primary goat anti-bfl-1 peptide antibody (1:100 dilution) (Santa Cruz Biotechnology Inc., Santa Cruz, California, USA), and a rat anti-mouse CD11b antibody as a mouse-specific marker for active microglia (1:25 dilution) (PharMingen). FITC-conjugated rabbit anti-rat IgG and lissamine-rhodamine-conjugated rabbit anti-goat IgG (Sigma-Aldrich) were used as secondary antibodies, as previously described (18).

Isolation, detection, and quantification of bfl-1-positive microglia/macrophages. Cells were isolated according to methods previously described (20). Briefly, mice were anesthetized with sodium pentobarbital (Nembutal;

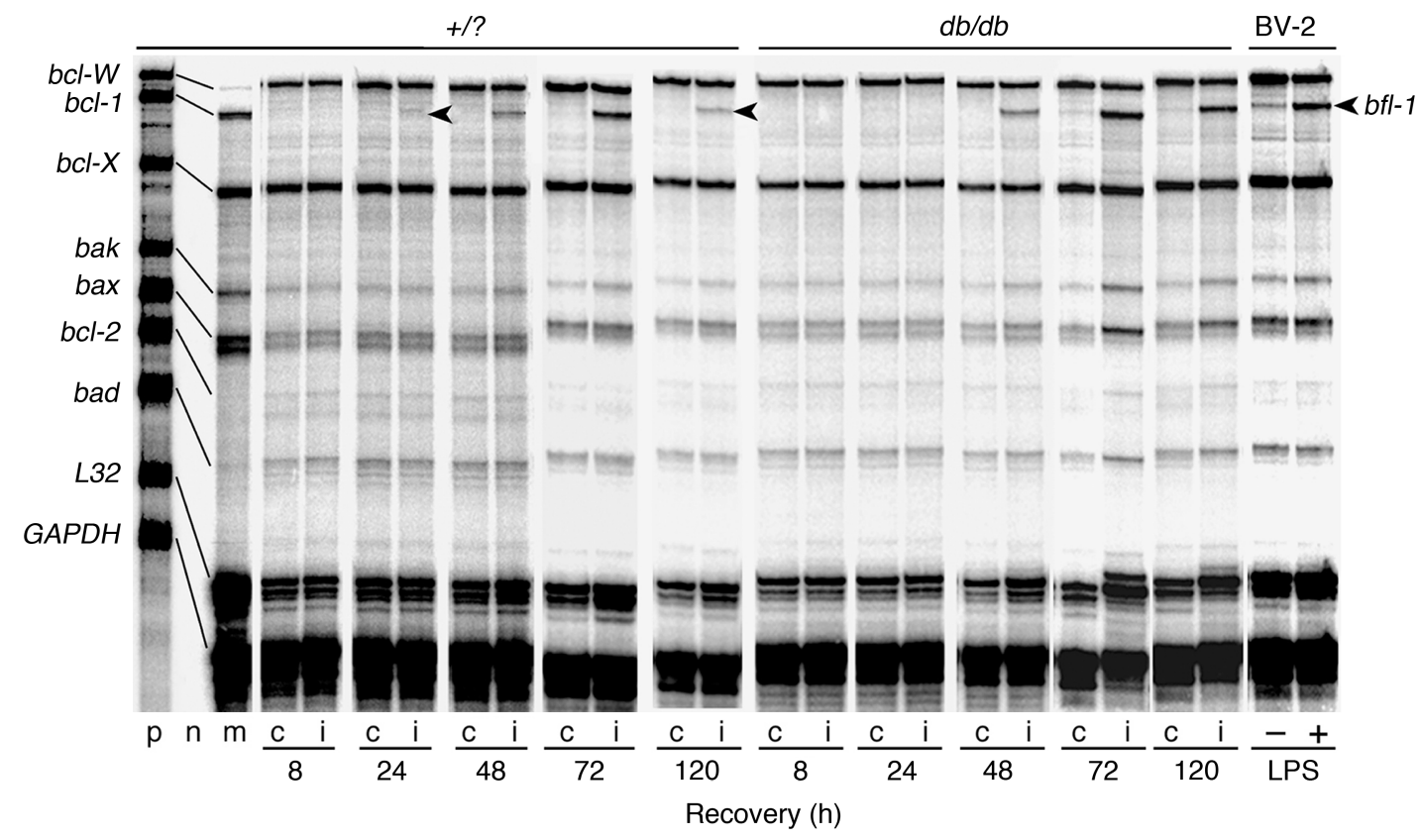

Figure 2

RPA for bcl-2 gene family following H/l: cortex. Total RNA was isolated from frozen tissue sections and from BV-2 cells (far right lanes), and analyzed by multiprobe RPA/ ${ }^{32} \mathrm{P}$. Purified samples were separated on a $6 \%$ urea-PAGE sequencing gel, and fragments were visualized by phosphorimage analysis and quantitated after normalization to the housekeeping gene GAPDH. Shown is a representative gel containing cortical samples for paired contralateral (c) and ipsilateral (i) hemispheres, from both nondiabetic ( $+/$ ?) and $d b / d b$ mice at recovery intervals from 8 to 120 hours. p, probes; $n$, negative control, yeast tRNA; $m$, mouse positive control. The far right lanes represent RNA prepared from BV-2 cells with or without LPS activation. Arrowheads indicate signal for bfl- 1 in ipsilateral hemispheres and LPS-treated BV-2 cells. 
Abbot Laboratories, North Chicago, Illinois, USA) and perfused with PBS. Brains were then removed, divided into ipsilateral and contralateral hemispheres, and placed in RPMI 1640 media supplemented with $10 \%$ (vol/vol) FBS, $50 \mu \mathrm{M}$ 2-mercaptoethanol, $2 \mathrm{mM}$ glutamine, $100 \mathrm{U} / \mathrm{ml}$ penicillin, and $100 \mu \mathrm{g} / \mathrm{ml}$ streptomycin sulfate. Brains were dissociated by passage through a 60 -gauge stainless steel mesh screen. The resulting cell suspension was layered onto a 35\%/70\% Percoll (Sigma-Aldrich) gradient and centrifuged at $2,000 \mathrm{~g}$. Mononuclear cells and neutrophils banded at the $35 \% / 70 \%$ interface and were collected and washed with supplemented RPMI 1640. Flow cytometric analysis of cell surface markers for microglia and macrophages was performed as described previously $(21,22)$. Briefly, Fc receptors on mononuclear cells were blocked with anti-CD16/32 antibody (1:100 dilution, clone 93; eBioscience, San Diego, California, USA) for $30 \mathrm{~min}-$ utes on ice. Following washes with FACS buffer (PBS supplemented with $1 \%$ [vol/vol] FBS, $0.02 \%$ [wt/vol] sodium azide), cells were incubated with anti-CD11b FITC (1:100 dilution, clone M1/70; eBioscience) and anti-CD45 phycoerythrin (1:100 dilution, clone 30-F11; eBioscience) for 20 minutes on ice. To determine the intracellular expression of bfl-1, cells were fixed in $2 \%$ (wt/vol) paraformaldehyde/PBS for 20 minutes at room temperature and subsequently incubated (30 minutes on ice) with anti-bfl-1 [affinity-purified A1(T-18); Santa Cruz Biotechnology Inc.] coupled with phycoerythrin-Cy5 (Amersham Pharmacia Biotech, Piscataway, New Jersey, USA) diluted 1:5 in 0.05\% (wt/vol) saponin prepared in FACS buffer. Cells were then washed with FACS buffer and resuspended in 2\% (wt/vol) paraformaldehyde/PBS for three-color flow cytometric analysis. Cells were analyzed using a FACScan flow cytometer (Becton Dickinson Immunocytometry Systems, Franklin Lakes, New Jersey, USA) equipped with a 488-nm argon laser. Ten thousand events were counted, and microglia were differentiated from macrophages based on the levels of CD11b and $\mathrm{CD} 45$ expression (microglia are $\mathrm{CD} 11 \mathrm{~b}^{+} \mathrm{CD} 45^{\text {low }}$ while macrophages are $\left.\mathrm{CD} 11 \mathrm{~b}^{+} \mathrm{CD} 45^{\text {high }}\right)$.

Statistical analysis. Data were analyzed by Student's $t$ test or ANOVA with Tukey analysis for multiple comparisons, and significance was assumed at $P \leq 0.05$. In the case of the flow cytometric analysis, each sample represented the pool of two to three hemispheres, preventing statistical analysis.

\section{Results}

The physiologic parameters of the $+/$ ? and $d b / d b$ mice are presented in Table 1. Diabetic mice weighed significantly more than their nondiabetic littermates and were hyperglycemic with circulating blood glucose levels of 20-22 mM/l, but there was no effect

Table 1 $+/ ?$ of diabetes on levels of plasma estradiol. Ovariectomy reduced the level of circulating estradiol equivalently in both groups. Estradiol replacement restored circulating levels to the physiologic range but did not affect blood glucose values or body weight in either group. Thus, at the time of the $\mathrm{H} / \mathrm{I}$ insult, respective OVX and $\mathrm{OVX}+\mathrm{E}$ animals were equivalent except for the presence of the obese diabetic state in the $d b / d b$ mice. To avoid animal variation due to stages of the estrus cycle, only OVX mice with and without estrogen replacement were subjected to $\mathrm{H} / \mathrm{I}$.

As previously described, this model of $\mathrm{H} / \mathrm{I}$ in the adult mouse produces selective cell death or infarction in cortex, striatum, and hippocampus in the hemisphere ipsilateral to the ligation (4). The effects of estradiol on the evolution of the brain damage in nondiabetic and diabetic mice, expressed as infarct fraction, are depicted in Figure 1. At all time points examined, estradiol reduced the extent of damage in the $+/$ ? mice (Figure 1a) to 15-20\%, a level of infarction comparable to that in our previous report in intact $+/$ ? females (4). Diabetes significantly enhanced the extent of damage in both OVX and OVX+E groups, relative to their nondiabetic littermates (Figure $1 \mathrm{~b}$ ). When mice were examined at 24 hours of recovery, estradiol treatment appeared to be neuroprotective; however, the damage continued to evolve such that no neuroprotective effect was observed at 48 hours and all diabetic mice exhibited more than $50 \%$ infarction through 5 days.

To determine whether diabetes affected the expression of the $b c l-2$ gene family following $\mathrm{H} / \mathrm{I}$, levels of $b c l-W, b f l-1$, $b c l-X, b a k, b a x, b c l-2$, and bad expression were analyzed by RPA of total RNA prepared from the tissue sections corresponding to the samples described in Figure 1. A representative gel for cortical samples is depicted in Figure 2. The far right lanes contain RNA prepared from BV-2 cells with and without activation by LPS. Band intensities were quantitated using phosphorimage analysis, and values were normalized against the housekeeping gene GAPDH. Levels of gene expression in pre-H/I animals were not different between $+/$ ? and $d b / d b$ mice (data not shown), and there was no increase in expression in any of the genes analyzed in the contralateral hemispheres of

Physiologic parameters of nondiabetic, $+/$ ?, and diabetic, $d b / d b$, mice Body weight $(\mathrm{g})$ Blood glucose $(\mathrm{mM} / \mathrm{l})$ Plasma estrogen $(\mathrm{pg} / \mathrm{ml})$

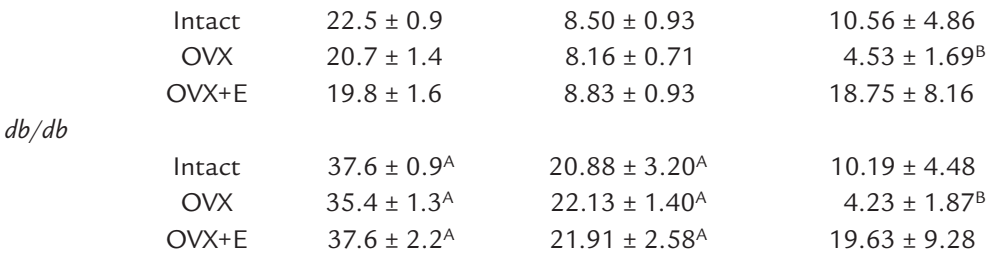

Body weight, blood glucose levels, and plasma estrogen levels were determined in intact $+/$ ? and $d b / d b$ mice at 8 weeks of age, as well as in both cohorts of mice following ovariectomy (OVX) and ovariec-

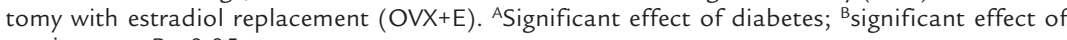
ovariectomy, $P<0.05$. 

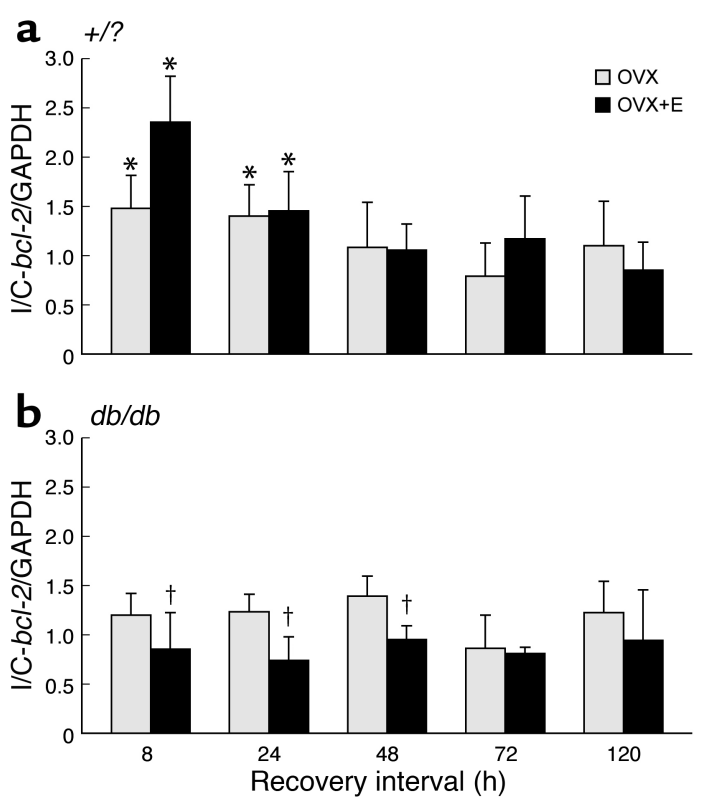

Figure 3

$B c /-2$ expression following $\mathrm{H} / \mathrm{I}$ in $+/$ ? and $d b / d b$ brains: effect of estrogen. Total RNA was analyzed by RPA. Levels of $b c l-2$ gene expression in both contralateral and ipsilateral hemispheres were adjusted for variations in loading by normalization to the housekeeping gene GAPDH. Levels of expression in contralateral hemispheres were not different from those in pre- $\mathrm{H} / \mathrm{I}$ controls, so levels of expression in the ischemic ipsilateral hemispheres were calculated relative to those in their paired contralateral hemisphere and were expressed as the mean ipsilateral/contralateral $(\mathrm{I} / \mathrm{C})$ ratio $\pm \mathrm{SD}$ for nondiabetic $+/$ ? (a) and $d b / d b$ mice (b). ${ }^{*}$ Significantly different from contralateral hemisphere, i.e., I/C $>1$; ${ }^{\dagger}$ significant effect of diabetes, relative to similarly treated $+/$ ?,$P<0.05$.

either group following $\mathrm{H} / \mathrm{I}$; ipsilateral/contralateral ratios were calculated for each animal. Significant differences were observed for two antiapoptotic genes, $b c l-2$ and $b f l-1$, as presented graphically in Figures 3 and $4 . B c l-2$ expression was increased (i.e., the ipsilateral/contralateral ratio was significantly greater than 1 ) in $+/$ ? mice at both 8 and 24 hours of reperfusion, with enhancement by estradiol at 8 hours (Figure 3a). These results were in sharp contrast to the observations in the diabetic animals (Figure $3 \mathrm{~b}$ ), in which the $\mathrm{H} / \mathrm{I}$-induced increase in $b c l-2$ expression was not observed, nor was there an effect of estrogen replacement. Similar changes were observed in both striatum and hippocampus (data not shown). The $b c l-2$ response observed in the normoglycemic mice following $\mathrm{H} / \mathrm{I}$ was in agreement with previous reports following middle cerebral artery occlusion (MCAO) (9); however, this response was absent in the $d b / d b$ mice. The most prominent effect of $\mathrm{H} / \mathrm{I}$ on gene expression was observed for another antiapoptotic member of the $b c l-2$ family, bfl-1 (Figure 4). Bfl-1 was not detected in pre-H/I samples from either $+/$ ? or $d b / d b$ brain (data not shown), and, as can be seen from the autoradiogram of Figure 2, there was no increase in expression in the contralateral hemisphere in either $+/$ ? or $d b / d b$ animals. $\mathrm{H} / \mathrm{I}$ resulted in significant increases in bfl-1 expression in nondiabetic animals at 8-24 hours of recovery; estradiol enhanced this effect (Figure 4a). Bfl-1 expression remained significantly elevated throughout 5 days of recovery, with an unexplained decrease in the OVX animals at 5 days of recovery. Again, the results observed in the diabetic animals were quite different (Figure 4b). There was no significant increase in expression in the diabetic brain until 48 hours of recovery, with no significant effect of estrogen replacement. As for Figure 3, the results presented were from cortical samples but were not different from the results from striatum and hippocampus (data not shown).

Expression of $b f l-1$ in brain has not been previously reported. Thus, it was important to determine the cellular expression of this antiapoptotic family member. Bfl-1 mRNA was analyzed by in situ hybridization using cryosections adjacent to those used for determination of infarct fraction; representative autoradiograms from estradiol-treated mice are presented in Figure 5. Consistent with the RPA data (Figure 4), bfl-1 mRNA was apparent at 8 hours of recovery in the ipsilateral hemisphere of $+/$ ? brains, with increasing expression in striatum and cortex during recovery. The timing, extent, and pattern of $b f l-1$ expression in the $d b / d b$ brains were clearly different, with very low levels of signal seen through the initial 48 hours, and, rather than appearing in cells throughout the affected tissue, the positive cells in the diabetic brain were predominantly at the border of the evolving infarct. To determine whether bfl-1 mRNA was further translated into protein, immunohistochemistry using an antibody to bfl- 1 was performed following in situ hybridization. The high-
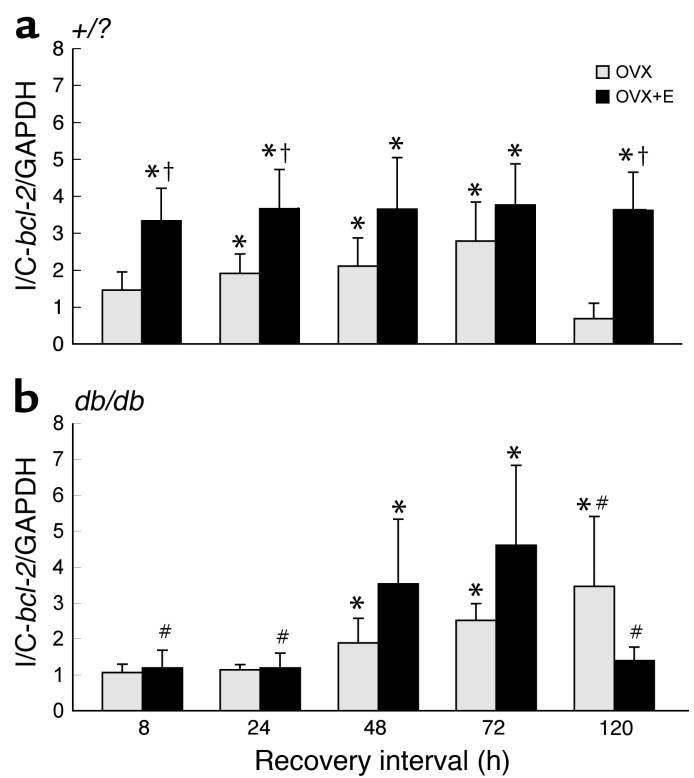

\section{Figure 4}

Bfl-1 expression following $\mathrm{H} / \mathrm{I}$ in $+/$ ? and $d b / d b$ brains: effect of estrogen. Levels of $b \mathrm{fl}-1$ were calculated as described in the legend to Figure 3. (a) +/?; (b) $d b / d b$. * Significant effect of estrogen; †significantly different from contralateral hemisphere; ${ }^{*}$ significant effect of diabetes, $P<0.05$. 


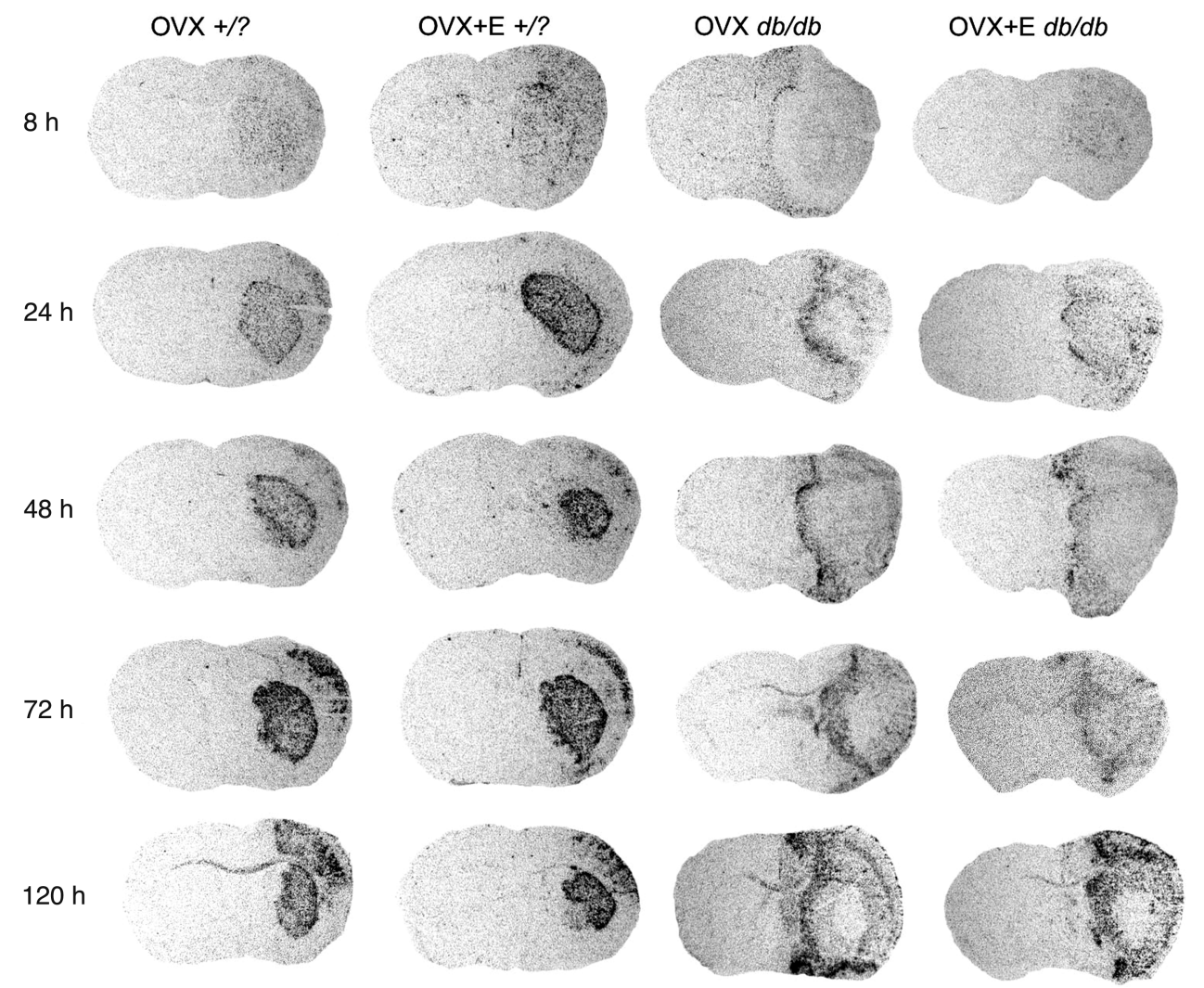

\section{Figure 5}

bfl-1 mRNA expression in $+/$ ? and $d b / d b$ brains following $\mathrm{H} / \mathrm{I}$. Sixteen-micrometer cryosections adjacent to those analyzed for infarct fraction (depicted in Figure 1) were analyzed for bfl-1 mRNA expression by in situ hybridization using ${ }^{35} S$-labeled riboprobes, as described in Methods. Shown are autoradiograms of representative coronal sections at the level of the striatum for OVX and OVX $+\mathrm{E},+/$ ? and $d b / d b$.

power, bright-field photomicrograph of an emulsiondipped slide demonstrates $b f l-1 \mathrm{mRNA}$ and protein in the same cells (Figure 6).

To determine which neural cell types express $b f l-1$, representative slides were analyzed by immunohistochemistry for the cell-specific markers GFAP (astrocytes), TG2 (neurons), and GSA I-B 4 Griffonia lectin (microglia/ macrophages) (Figure 7). Bfl-1 mRNA colocalized with some, but not all, lectin-positive cells (arrows), indicative of a microglial/macrophage expression (Figure 7, a and b). bfl-1-positive cells (arrows) did not colocalize to either GFAP-positive (Figure 7, c and d) or TG2-positive cells (Figure 7, e and f) (arrowheads), suggesting that bfl-1 may be restricted to microglia/macrophages. Since we recently demonstrated that IGF-1 mRNA expression is markedly increased in microglia/macrophages following $\mathrm{H} / \mathrm{I}$ in the mouse brain (17), we also analyzed IGF-1 mRNA expression by in situ hybridization analysis of cryosections adjacent to those presented in Figure 5. We observed a strikingly similar pattern of distribution between IGF-1 mRNA and $b f l-1$ mRNA, with IGF-1 appearing in cortex and striatum of $+/$ ? mice as early as 24 hours after $\mathrm{H} / \mathrm{I}$ (data not shown) and achieving a robust level of expression by 3-5 days (Figure 8). IGF-1 mRNA was barely detectable in the $d b / d b$ brain during the early intervals of reperfusion (data not shown) and was only apparent in association with the edge of the infarct at a later time. For comparison, Figure 8 depicts autoradiographic images of in situ hybridization analyses for $b f-1$ and IGF- 1 using adjacent coronal sections, at the levels of the anterior hippocampus and the striatum, in $+/ ?$ and $d b / d b$ mice at 5 days following $\mathrm{H} / \mathrm{I}$. The pattern of IGF-1 expression in the brain of the $+/$ ? mouse is identical to what we previously demonstrated to be attributable to microglia/macrophages (17), and the comparison of IGF-1 and bfl-1 expression shown in Figure 8 lends further support to a microglial/macrophage expression of $b f l-1$.

Although the studies described above suggest that bfl- 1 is primarily expressed by microglia/macrophages, they do not differentiate between expression in resident microglia and expression in invading macrophages. To this end, cells isolated from ipsilateral and contralateral hemispheres from both $+/$ ? and $d b / d b$ mice at 24 and 48 hours of recovery were subjected to flow cytometric analysis and separated based on their levels of CD 45/CD11b expression, with and without subsequent analysis for bfl-1 (Figure 9). To obtain sufficient cell numbers to perform these studies, ipsilateral and contralateral hemispheres from two to three similarly treated animals were pooled, and thus the data in Figure 9 represent the average values for three to four hemispheres. At 24 hours of recovery, the number of microglia in the nondiabetic brain was 


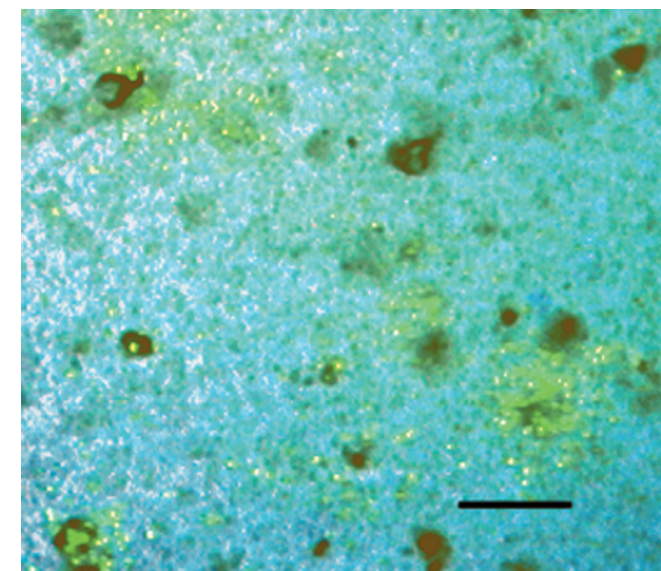

Figure 6

Colocalization of $b f-1$ mRNA and protein. To determine whether the bfl-1 mRNA depicted in Figure 5 was translated into protein, select slides were subjected to immunohistochemical analysis of $b f-1$ protein expression. Positive mRNA signal was visualized by epiluminescent microscopy (green), and protein was visualized with diaminobenzidine (brown). Scale bar: $50 \mu \mathrm{m}$.

approximately twice that in the diabetic animals, with a comparable increase in the number of bfl-1-positive microglia in these animals (Figure 9, a and c). The number of microglia detected did not appreciably change by 48 hours, except for a sharp reduction in the contralateral hemisphere of the nondiabetic mice. This finding is in sharp contrast to the patterns observed for macrophages (Figure 9, b and d). Invading macrophages were minimally detected in the nondiabetic brains at either 24 or 48 hours, and bfl-1positive macrophages were even fewer, consistent with less damage and no breakdown of the blood-brain barrier. However, in the diabetic brains, by 48 hours there was a dramatic increase in the number of macrophages in the damaged hemisphere as well as an increase in the number of bfl-1-positive macrophages. These observations are consistent with the temporal detection of bfl-1 expression (Figure 4) and its localization to the border of the infarct as part of the gliotic scar (Figure 5).

Finally, to address whether $b f l-1$ expression is increased by stimulation of microglia, $b f l-1$ expression was investigated in the BV-2 microglial cell line, both with and without activation by LPS. The expression of the $b c l-2$ family members in these cells after 6 hours of LPS stimulation is presented in the two right lanes of Figure 2. The quantitation of $b f l-1$ revealed a sixfold increase in expression (data not shown). Both the expression of $b f l-1$ by a microglial cell line, and the rapid increase in this expression with LPS stimulation, add more support to the contention that rapid expression of the antiapoptotic bfl-1 is a component of the microglial response to activation.

\section{Discussion}

The four major findings of this study are (a) that estrogen administration is protective against hypoxicischemic brain damage in normoglycemic C57BL/KsJ
+/? mice, but not in their type 2 diabetic counterparts; (b) that estrogen stimulates post-H/I bcl-2 expression in normoglycemic but not diabetic $d b / d b$ mice; (c) that bfl- 1 is expressed in brain microglia following $\mathrm{H} / \mathrm{I}$; and (d) that the microglial response to $\mathrm{H} / \mathrm{I}$ is reduced in the diabetic brain. These findings have significant implications for both the efficacy of estrogen administration in diabetic females, and the role of microglia and macrophages in the recovery from stroke in diabetic, as well as nondiabetic, animals.

The protective effect of estrogen administration in experimental models of ischemic stroke is well established $(8,23)$. However, whether estrogen-mediated protection extends to the diabetic is still controversial $(4,24$, $25)$. In the $\mathrm{BB}$ rat, a genetic model of type 1 diabetes, male diabetics sustained greater infarcts following transient MCAO, despite insulin-controlled normoglycemia, and chronic estrogen treatment was neuroprotective in these diabetic animals (24). In the same study, diabetes did not increase the extent of infarction in normoglycemic, intact, female BB diabetic rats, relative to nondiabetic females. However, damage was evaluated at only 24 hours of recovery, and the possibility of a further evolution of infarction, as seen in the present study (Figure $1 b)$, was not investigated. More recently, the efficacy of
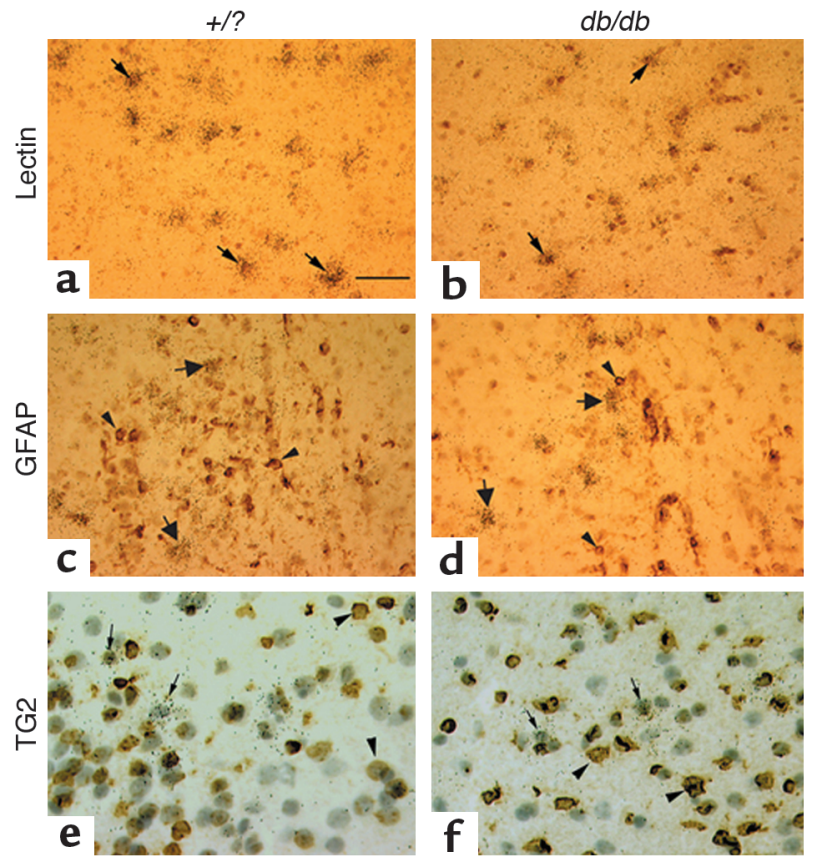

\section{Figure 7}

Bfl-1 mRNA colocalizes with GSA I- B $_{4}$ Griffonia lectin-positive but not with GFAP- or TG2-positive cells. Following in situ hybridization for $b f f-1$, slides were analyzed for protein expression of GSA I-B ${ }_{4}$ Griffonia lectin (microglia/macrophages; $\mathbf{a}$ and b), GFAP (astrocytes; $\mathbf{c}$ and $\mathbf{d}$ ), or TG2 (neurons; $\mathbf{e}$ and $\mathbf{f}$ ) by immunohistochemistry. Slides were exposed to photographic emulsion and developed. Silver grains depict positive bfl-1 mRNA hybridization; protein is brown (diaminobenzidine). Shown are representative sections from striatum of $+/$ ? OVX+E (a, c, and $\mathbf{e})$ and $d b / d b$ OVX $+E$ mice $(\mathbf{b}, \mathbf{d}$, and $\mathbf{f})$ at 48 hours of recovery. Arrows, $b f l-1$ mRNA; arrowheads, respective protein. Scale bar: $50 \mu \mathrm{m}$. 

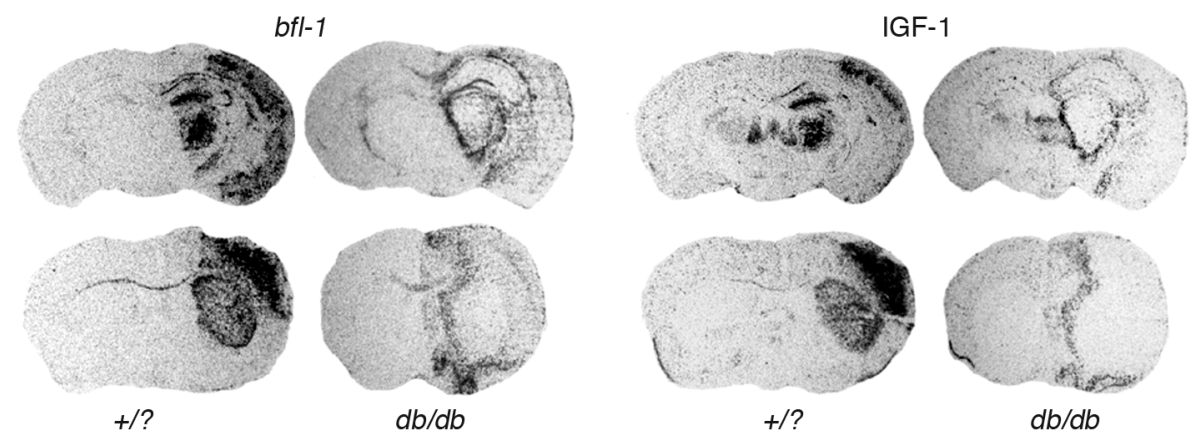

Figure 8

Bfl-1 and IGF-1 mRNA in $+/$ ? and $d b / d b$ brains following $\mathrm{H} / \mathrm{I}$. Sixteen-micrometer cryosections adjacent to those analyzed for infarct fraction (depicted in Figure 1) were analyzed for IGF-1 mRNA expression by in situ hybridization using ${ }^{35}$ S-labeled riboprobes, as described in Methods. Shown are autoradiograms of representative coronal sections adjacent to sections analyzed for bfl-1 mRNA at the level of the anterior hippocampus (top row) and striatum (bottom row) in $+/$ ? and $d b / d b(\mathrm{OVX}+\mathrm{E})$ mice at 5 days of recovery from $\mathrm{H} / \mathrm{I}$.

estrogen administration in females was evaluated following transient $\mathrm{MCAO}$ in another model of type 1 diabetes, the streptozotocin rat (25). Evaluation of neurologic function and damage at 72 hours of recovery following a short period of occlusion (20 minutes) suggested that estrogen replacement actually exacerbates the effects of the stroke. However, there were no comparisons with nondiabetic females or males similarly treated to determine whether endogenous circulating hormones are protective in the intact diabetic female. Clinically, stroke is more prevalent in patients with type 2 diabetes $(26,27)$, and the genetically hyperinsulinemic/hyperglycemic $d b / d b$ mouse used in the studies presented here is an accepted model of type 2 diabetes. We previously reported that although diabetes worsened hypoxic-ischemic brain damage in males and females, both female control and $d b / d b$ mice were significantly protected relative to their male counterparts (4). In the present study, we specifically investigated the role of hormonal removal by ovariectomy, followed by estrogen replacement. Hypoxic-ischemic damage was exacerbated by ovariectomy in nondiabetic $+/$ ? mice, and this was reversed by estrogen administration. Estrogen-induced neuroprotection was observed as early as 8 hours of reperfusion and was maintained through 5 days, with no further increase in infarct fraction beyond 24 hours (Figure 1a). These results are consistent with previous reports following MCAO in nondiabetic mice and rats $(28,29)$ and, importantly, support a lasting neuroprotective effect of estrogen in the nondiabetic female. Hypoxic-ischemic damage in the $d b / d b$ was also exacerbated by ovariectomy, resulting in nearly total infarction in the ischemic hemisphere. Although estrogen administration did appear to protect the diabetic female brain during the first 24 hours of recovery, the damage continued to evolve during the next 24 hours, rendering both OVX and OVX+E diabetic groups equally damaged at 2-5 days (Figure $1 \mathrm{~b})$. These results suggest that there may have been an acute protective effect of estrogen administration, albeit insufficient to overcome the deleterious effect of diabetic hyperglycemia on delayed cell death.

Several mechanisms have been proposed to underlie estrogen-mediated neuroprotection, including both vascular, i.e., perfusion-dependent, and perfusion-independent effects (reviewed in refs. 8, 30). Estrogen is a potent vasodilator, and preservation of $\mathrm{CBF}$ has been demonstrated in several experimental models of global ischemia. However, end-hypoxic-ischemic CBF is not different among male and female, $+/$ ? and $d b / d b$ mice,
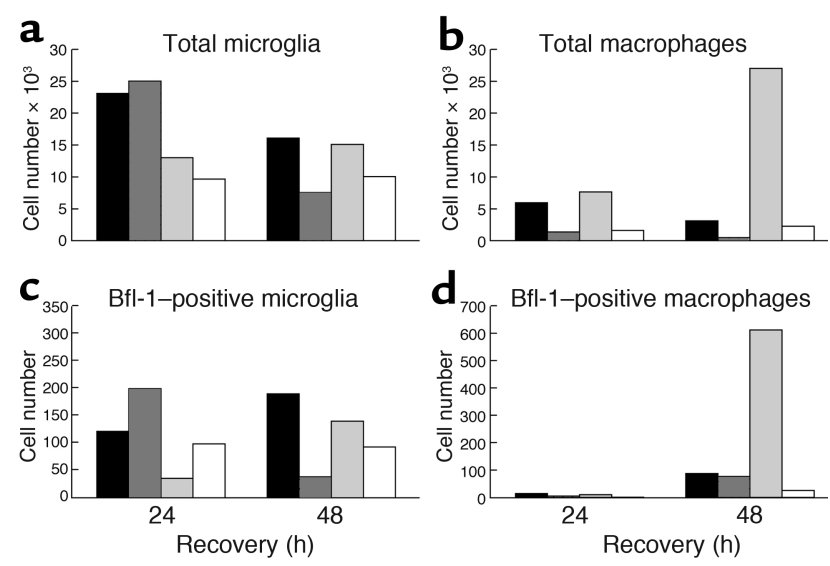

\section{Figure 9}

Flow cytometric analysis of microglia and macrophages in $+/$ ? and $d b / d b$ mice following $\mathrm{H} / \mathrm{l}$. Mice underwent $\mathrm{H} / \mathrm{I}$, and brains were removed 24 and 48 hours after surgery. Brains of both $+/$ ? and $d b / d b$ mice were divided into damaged (ipsilateral) and undamaged (contralateral) hemispheres. Mononuclear cells from the pooled hemispheres of two to four mice per group were isolated by a Percoll gradient and processed for simultaneous detection of CD11 and CD45, with bfl-1, as described in Methods. Ten thousand events per sample were analyzed by fluorescent flow cytometry. ( $\mathbf{a}$ and $\mathbf{b}$ ) Total microglia (a) and macrophages (b) per hemisphere. (c and $\mathbf{d}$ ) The number of microglia (c) and macrophages (d) that are $b f f-1$ positive. Black bars, $+/$ ? ipsilateral; dark gray bars, + /? contralateral; light gray bars, $d b / d b$ ipsilateral; white bars, $d b / d b$ contralateral. 
indicating that vascular effects are not the basis for estrogen-mediated neuroprotection in this model (4). Of the several potential perfusion-independent mechanisms, stimulation of $b c l-2$ expression, presumably accompanied by inhibition of apoptotic cell death, has been highlighted $(9,10)$. A recent report demonstrated that estrogen administration enhanced the normally occurring increase in bcl-2 mRNA and protein levels observed in penumbral neurons following $\mathrm{MCAO}$ in rats, and that ischemic damage in female mice that overexpressed neuronal $b c l-2$ was not worsened by ovariectomy (9). Our original hypothesis was that a bcl-2mediated antiapoptotic mechanism is relevant in the female diabetic brain, since early studies in male rats reported that hyperglycemia exacerbated postischemic brain damage by an ongoing expansion of cell death in the penumbra $(11,13,31)$. Consistent with previous reports $(9,10), b c l-2$ levels increased in the ipsilateral hemisphere of nondiabetic mice at 8 and 24 hours following $\mathrm{H} / \mathrm{I}$, and estrogen-mediated neuroprotection was associated with enhancement of this effect (Figure 3a). A comparable increase in $b c l-2$ levels was not observed in the female $d b / d b$ brain (Figure $3 b$ ), although whether this was due to a defect in estrogen signaling or due to another effect of the diabetic/hyperglycemic state is beyond the scope of this study.

The other major - and, to our knowledge, completely novel - finding of this study is expression of another antiapoptotic member of the $b c l-2$ family, $b f l-1$, in cells characteristic of microglia/macrophages. $\mathrm{H} / \mathrm{I}$ induced bfl- 1 expression by 8 hours of reperfusion in the nondiabetic female brain, and estrogen administration enhanced this effect. Similar to the response of $b c l-2, b f l-1$ expression in the diabetic brain was not induced during the initial 24 hours of recovery, and there was no effect of estrogen administration. Bfl- 1 was later induced in the diabetic brain, but not until 48 hours following the insult, when the infarct was fully developed. The results presented in the in situ hybridization autoradiograms (Figure 5) support an additional difference between $b f l-1$ expression in the $+/ ?$ and that in the $d b / d b$ brain. bfl-1positive cells were evident early in reperfusion throughout the ischemic hemisphere in the nondiabetic brain, whereas the delayed expression seen in the diabetic brain was detected in cells that surround the border of the infarct, indicative of a gliotic scar.

$B f-1$ is a relatively newly described antiapoptotic member of the $b c l-2$ gene family, which encodes a 175 -amino acid polypeptide, originally cloned from mouse bone marrow (15). In normal tissues, bfl- 1 mRNA is detected only in bone marrow, lymphoid organs, peripheral leukocytes, and lung (32-34) and is overexpressed in human epithelial and hematopoietic malignancies (35, 36). $B f l-1$ is robustly induced in myeloid and endothelial cells in vitro following activation by the proinflammatory stimuli TNF- $\alpha$ and IL- $1 \beta$ and has been shown to protect these cells from apoptosis (33, 37-39). Bfl-1 lacks the necessary hydrophobic carboxyl-terminal region to interact with mitochondria directly but exerts its anti- apoptotic effect by binding to $\mathrm{Bid}$, a proapoptotic $\mathrm{BH} 3$ domain-only protein, and remaining bound even after activation and cleavage by caspase-8, thus preventing formation of the proapoptotic complex and release of cytochrome $c$ (40). Bfl-1 expression may be directly regulated by the transcription factor NF-KB $(33,41,42)$, which is activated in microglia in response to TNF- $\alpha$ production (43). The present study is, to our knowledge, the first report of $b f l-1$ expression in the brain, and the localization of $b f l-1$ to microglia is consistent with its expression in cells of the monocyte/macrophage lineage. The early (8 hours) appearance of $b f l-1$, especially in the less damaged brains, which would be expected to have less breakdown of the blood-brain barrier, supports primary expression in resident microglia (44). Flow cytometric analysis of bfl-1-positive cells (Figure 9) confirms the early microglial expression in postischemic brain from $+/$ ? mice, observed in association with tissue recovery in these animals. If such microglial activity represents a neuroprotective function, then the lack of this activity in the postischemic brain from the $d b / d b$ mice suggests a major diabetes-related difference in ischemic response. The delayed bfl- 1 seen in the diabetic brain is due to invading macrophages in association with infarction. Studies of pro- and antiapoptotic activity in ischemic brain have routinely focused on neurons. However, the expression of the antiapoptotic protein bfl-1 in microglia suggests that resistance to pro-death stimuli active in the postischemic cerebral environment is important in this cell population as well.

It has been widely accepted that the presence of activated microglia indicates neurodegeneration and death. However, there is growing evidence both in vitro and in vivo that microglia, components of the endogenous immune system of the brain, serve neuroprotective functions as well (45). Microglia in vitro can secrete growth factors, such as bFGF and nerve growth factor, which are known to enhance survival and neurite outgrowth of different types of CNS neurons $(46,47)$. We recently demonstrated an upregulation of IGF-1 expression in microglial cells following $\mathrm{H} / \mathrm{I}$ and further demonstrated that IGF-1 is a potent mitogen for microglia. These findings support an autocrine/paracrine role for this growth factor in the ischemic brain (17). We have now confirmed the same pattern of IGF-1 mRNA expression in the postischemic nondiabetic brain and have demonstrated that this pattern closely corresponds to bfl-1 expression (Figure 8). Thus, it is likely that microglia can respond to a period of cerebral ischemia by increasing their expression of $b f l-1$ and IGF-1, resulting in a self-protection from apoptotic cell death and perhaps providing neuroprotection. The enhancement of the $b f l-1$ response by estrogen treatment suggests another potential neuroprotective mechanism for this steroid hormone. Microglia express the ER- $\beta$ estrogen receptor (48), and microglia in the hypothalamus are activated during the estrous cycle or in response to a single estradiol injection (49). Equally, the failure of an early microglial response in the diabetic brain may contribute to increased infarction. 
The question then arises as to why microglia in the diabetic brain do not express $b f-1$ or IGF- 1 in response to $\mathrm{H} / \mathrm{I}$. The answer can best be appreciated in the context of more common complications of diabetes. Frequent complications of both type 1 and type 2 diabetes include increased susceptibility to infection and impaired wound healing, both of which have been attributed to defects in peripheral macrophage function (as discussed in ref. 50 and references therein). Specific defects in peritoneal macrophages isolated from $d b / d b$ mice include altered morphology, reduced release of both VEGF and cytokines following LPS stimulation, and reduced phagocytosis (50). Dermal wound healing is impaired in diabetic animals $(51,52)$, and the close resemblance to what is seen in macrophagedepleted animals (53) led to the hypothesis that macrophages contribute cytokines and growth factors essential to proper tissue repair. IGF-1 mRNA and protein are both delayed and reduced in peripheral wounds in $d b / d b$ mice (54), which is similar to the situation we observed in the postischemic $d b / d b$ brain (Figure 8). The defects in nonspecific immunity observed in these mice have been attributed to the central role of leptin in mediating the immune response and the lack of functional leptin in these metabolic syndromes (reviewed in ref. 51). Leptin administration ameliorates the delay in dermal wound healing in the leptin-deficient ob/ob mouse, but not in the $d b / d b$ mouse, which lacks a functional leptin receptor (55). Leptin has been shown to have both proliferative and antiapoptotic effects on a variety of cell types, including human and murine $\mathrm{T}$ lymphocytes (56) and murine thymocytes (57). It is tempting to speculate that leptin may similarly affect microglia in the early stages of recovery from cerebral $\mathrm{H} / \mathrm{I}$ and thus be involved in a neuroprotective function of the immune cells of the brain. Although specific deficits in leptin levels or signaling were first characterized in $o b / o b$ and $d b / d b$ mice, similar deficits are characteristic of diabetes in general (58). A delayed $b f l-1 /$ gliotic response was observed in streptozotocin-treated diabetic rats following permanent MCAO (I.A. Simpson and S.J. Vannucci, unpublished observations), indicating that impaired microglial/ macrophage response following stroke is characteristic of other forms of diabetes as well. A defect in the peripheral macrophage response in the diabetic could be assumed based on the above-mentioned studies, but the results presented here lead to the novel hypothesis that there is a defect in the brain microglial response, and specifically a potentially neuroprotective response, that exacerbates ischemic damage in the diabetic.

In conclusion, this study has addressed the complex interaction of diabetes and estrogen treatment in a mouse model of cerebral $\mathrm{H} / \mathrm{I}$. We demonstrate that estrogen treatment is not protective in the OVX $d b / d b$ mouse, as it is in the $+/$ ? controls. The failure of estrogen to protect the diabetic brain relates, at least in part, to a failure of the antiapoptotic $b c l-2$ response and increased infarction. The additional novel finding of this study is the detection of another antiapoptotic protein, bfl-1, in activated microglia as part of an early response in post-H/I brain in $+/$ ? but not in diabetic mice. In contrast, bfl- 1 is observed in the post-H/I diabetic brain in association with invading macrophages after the infarct is established. Exogenous estrogen promotes the former, potentially neuroprotective, microglial response, but not the latter macrophage response. The expression of $b f l-1$ in microglia may offer a new tool to study the function of these cells in brain injury. Furthermore, the diabetes-associated delay in microglial activation, as indicated by $b f l-1$ induction, may indicate that impaired microglial function contributes to more extensive damage in the diabetic brain.

\section{Acknowledgments}

This work was supported by a research grant from the American Diabetes Association (to S.J. Vannucci). We would like to thank Lisa Willing and Wei Wei Wang for their expert technical assistance.

1. Jorgensen, H., Nakayama, H., Raaschou, H.O., and Olsen, T.S. 1994 Stroke in patients with diabetes. The Copenhagen Stroke Study. Stroke. 25:1977-1984.

2. Kannel, W., and Thorn, T. 1994. The incidence, prevalence and mortality of cardiovascular disease. In The heart. R. Schlant and R. Alexander, editors. McGraw-Hill. New York, New York, USA. 185-197.

3. Kuller, L.H. 1995. Stroke and diabetes. In Diabetes in America. National Dibetes Data Group, editors. U.S. Department of Health and Human Services, NIH, National Institute of Diabetes and Digestive and Kidney Diseases. NIH Publication 95-1468. 449-456

4. Vannucci, S.J., et al. 2001. Experimental stroke in the female diabetic, $d b / d b$, mouse. J. Cereb. Blood Flow Metab. 21:52-60.

5. Lee, G.H., et al. 1996. Abnormal splicing of the leptin receptor in diabetic mice. Nature. 379:632-635.

6. Chen, H., et al. 1996. Evidence that the diabetes gene encodes the leptin receptor: identification of a mutation in the leptin receptor gene in $d b / d b$ mice. Cell. 84:491-495.

7. Coleman, D.L. 1982. Diabetes-obesity syndromes in mice. Diabetes. 31:1-6.

8. Hurn, P.D., and Macrae, I.M. 2000. Estrogen as a neuroprotectant in stroke. J. Cereb. Blood Flow Metab. 20:631-652.

9. Alkayed, N.J., et al. 2001. Estrogen and $b c l-2$ : gene induction and effect of transgene in experimental stroke. J. Neurosci. 21:7543-7550.

10. Dubal, D.B., Shughrue, P.J., Wilson, M.E., Merchenthaler, I., and Wise, P.M. 1999. Estradiol modulates $b c l-2$ in cerebral ischemia: a potential role for estrogen receptors. J. Neurosci. 19:6385-6393.

11. Nedergaard, M., and Diemer, N.H. 1987. Focal ischemia of the rat brain, with special reference to the influence of plasma glucose concentration. Acta Neuropathol. (Berl.) 73:131-137.

12. Nedergaard, M., Jakobsen, J., and Diemer, N.H. 1988. Autoradiographic determination of cerebral glucose content, blood flow, and glucose utilization in focal ischemia of the rat brain: influence of the plasma glucose concentration. J. Cereb. Blood Flow Metab. 8:100-108.

13. Nedergaard, M. 1987. Transient focal ischemia in hyperglycemic rats is associated with increased cerebral infarction. Brain Res. 408:79-85.

14. Sawada, M., et al. 2000. Estrogen receptor antagonist ICI182,780 exacerbates ischemic injury in female mouse. J. Cereb. Blood Flow Metab. 20:112-118.

15. Lin, E.Y., Orlofsky, A., Berger, M.S., and Prystowsky, M.B. 1993. Characterization of A1, a novel hemopoietic-specific early-response gene with sequence similarity to bcl-2. J. Immunol. 151:1979-1988.

16. Vannucci, S.J., Gibbs, E.M., and Simpson, I.A. 1997. Glucose utilization and glucose transporter proteins GLUT-1 and GLUT- 3 in brains of diabetic $(d b / d b)$ mice. Am. J. Physiol. 272:E267-E274.

17. O'Donnell, S.L., Frederick, T.J., Krady, J.K., Vannucci, S.J., and Wood, T.L. 2002. IGF-I and microglia/macrophage proliferation in the ischemic mouse brain. Glia. 39:85-97.

18. Vannucci, S.J., et al. 1998. GLUT4 glucose transporter expression in rodent brain: effect of diabetes. Brain Res. 797:1-11.

19. Streit, W.J. 1990. An improved staining method for rat microglial cells using the lectin from Griffonia simplicifolia (GSA I-B4). J. Histochem. Cytochem. 38:1683-1686.

20. Anglen, C.S., Truckenmiller, M.E., Schell, T.D., and Bonneau, R.H. 2003. 
The dual role of CD8+ T lymphocytes in the development of stressinduced herpes simplex encephalitis. J. Neuroimmunol. 140:13-27.

21. Sedgwick, J.D., et al. 1991. Isolation and direct characterization of resident microglial cells from the normal and inflamed central nervous system. Proc. Natl. Acad. Sci. U. S. A. 88:7438-7442.

22. Fischer, H.G., and Reichmann, G. 2001. Brain dendritic cells and macrophages/microglia in central nervous system inflammation. J. Immunol. 166:2717-2726.

23. Roof, R.L., and Hall, E.D. 2000. Gender differences in acute CNS trauma and stroke: neuroprotective effects of estrogen and progesterone. J. Neurotrauma. 17:367-388

24. Toung, T.J., Traystman, R.J., and Hurn, P.D. 1998. Estrogen-mediated neuroprotection after experimental stroke in male rats. Stroke. 29:1666-1670.

25. Santizo, R.A., Xu, H.-L., Ye, S., Baughman, V.L., and Pelligrino, D.A. 2002. Loss of benefit from estrogen replacement therapy in diabetic ovariectomized female rats subjected to transient forebrain ischemia. Brain Res. 956:86-95.

26. Jorgensen, H.S., Sperling, B., Nakayama, H., Raaschou, H.O., and Olsen, T.S. 1994. Spontaneous reperfusion of cerebral infarcts in patients with acute stroke. Incidence, time course, and clinical outcome in the Copenhagen Stroke Study. Arch. Neurol. 51:865-873.

27. Jorgensen, H.S., Nakayama, H., Reith, J., Raaschou, H.O., and Olsen, T.S 1997. Stroke recurrence: predictors, severity, and prognosis. The Copenhagen Stroke Study. Neurology. 48:891-895.

28. Hurn, P.D., Littleton-Kearney, M.T., Kirsch, J.R., Dharmarajan, A.M., and Traystman, R.J. 1995. Postischemic cerebral blood flow recovery in the female: effect of 17 beta-estradiol. J. Cereb. Blood Flow Metab. 15:666-672.

29. Alkayed, N.J., Murphy, S.J., Traystman, R.J., Hurn, P.D., and Miller, V.M 2000. Neuroprotective effects of female gonadal steroids in reproductively senescent female rats. Stroke. 31:161-168.

30. Garcia-Segura, L.M., Azcoitia, I., and DonCarlos, L.L. 2001. Neuroprotection by estradiol. Prog. Neurobiol. 63:29-60.

31. Pulsinelli, W.A., Waldman, S., Rawlinson, D., and Plum, F. 1982. Moderate hyperglycemia augments ischemic brain damage: a neuropathologic study in the rat. Neurology. 32:1239-1246.

32. Choi, S.S., et al. 1995. A novel $b c l-2$ related gene, $b f l-1$, is overexpressed in stomach cancer and preferentially expressed in bone marrow. Oncogene. 11:1693-1698.

33. Zong, W.X., Edelstein, L.C., Chen, C., Bash, J., and Gelinas, C. 1999. The prosurvival $b c l-2$ homolog $b f l-1 / \mathrm{A} 1$ is a direct transcriptional target of NF-kappaB that blocks TNFalpha-induced apoptosis. Genes Dev. 13:382-387.

34. O'Reilly, M.A., et al. 2000. bcl-2 family gene expression during severe hyperoxia induced lung injury. Lab. Invest. 80:1845-1854.

35. Pang, X.P., Hershman, J.M., and Karsan, A. 1997. TNF-alpha induction of A1 expression in human cancer cells. Oncol. Res. 9:623-627.

36. D'Sa-Eipper, C., Subramanian, T., and Chinnadurai, G. 1996. bfl-1, a bcl-2 homologue, suppresses $\mathrm{p} 53$-induced apoptosis and exhibits potent cooperative transforming activity. Cancer Res. 56:3879-3882.

37. D'Sa-Eipper, C., and Chinnadurai, G. 1998. Functional dissection of $b f l-1$, a bcl-2 homolog: anti-apoptosis, oncogene-cooperation and cell proliferation activities. Oncogene. 16:3105-3114.

38. Karsan, A., Yee, E., and Harlan, J.M. 1996. Endothelial cell death induced by tumor necrosis factor-alpha is inhibited by the $b c l-2$ family member, A1. J. Biol. Chem. 271:27201-27204.
39. Perera, L.P., and Waldmann, T.A. 1998. Activation of human monocytes induces differential resistance to apoptosis with rapid down regulation of caspase-8/FLICE. Proc. Natl. Acad. Sci. U. S. A. 95:14308-14313.

40. Werner, A.B., de Vries, E., Tait, S.W., Bontjer, I., and Borst, J. 2002. bcl-2 family member $b f-1 /$ A 1 sequesters truncated bid to inhibit its collaboration with pro-apoptotic Bak or Bax. J. Biol. Chem. 277:22781-22788.

41. Grumont, R.J., Rourke, I.J., and Gerondakis, S. 1999. Rel-dependent induction of A1 transcription is required to protect B cells from antigen receptor ligation-induced apoptosis. Genes Dev. 13:400-411

42. Lee, H.-W., et al. 2002. 4-1BB promotes the survival of CD8+ T lymphocytes by increasing expression of $B c l-x L$ and $b f l-1$. J. Immunol. 169:4882-4888.

43. Nguyen, V.T., and Benveniste, E.N. 2002. Critical role of tumor necrosis factor-alpha and NF-kappa B in interferon-gamma-induced CD40 expression in microglia/macrophages. J. Biol. Chem. 277:13796-13803.

44. Gehrmann, J., Banati, R.B., Wiessner, C., Hossmann, K.A., and Kreutzberg, G.W. 1995. Reactive microglia in cerebral ischaemia: an early mediator of tissue damage? Neuropathol. Appl. Neurobiol. 21:277-289.

45. Streit, W.J. 2002. Microglia as neuroprotective, immunocompetent cells of the CNS. Glia. 40:133-139.

46. Araujo, D.M., and Cotman, C.W. 1992. Basic FGF in astroglial, microglial, and neuronal cultures: characterization of binding sites and modulation of release by lymphokines and trophic factors. J. Neurosci. 12:1668-1678.

47. Mallat, M., Houlgatte, R., Brachet, P., and Prochiantz, A. 1989 Lipopolysaccharide-stimulated rat brain macrophages release NGF in vitro. Dev. Biol. 133:309-311.

48. Mor, G., et al. 1999. Estrogen and microglia: a regulatory system that affects the brain. J. Neurobiol. 40:484-496.

49. Brawer, J.R., Schipper, H., and Naftolin, F. 1980. Ovary-dependent degeneration in the hypothalamic arcuate nucleus. Endocrinology. 107:274-279.

50. Zykova, S.N., et al. 2000. Altered cytokine and nitric oxide secretion in vitro by macrophages from diabetic type II-like $d b / d b$ mice. Diabetes. 49:1451-1458.

51. Fantuzzi, G., and Faggioni, R. 2000. Leptin in the regulation of immunity, inflammation, and hematopoiesis. J. Lenkoc. Biol. 68:437-446.

52. Greenhalgh, D.G., Sprugel, K.H., Murray, M.J., and Ross, R. 1990. PDGF and FGF stimulate wound healing in the genetically diabetic mouse. Am J. Pathol. 136:1235-1246.

53. Leibovich, S.J., and Ross, R.R. 1975. The role of the macrophage in wound repair. A study with hydrocortisone and antimacrophage serum. Am. J. Pathol. 78:71-100.

54. Brown, D.L., Kao, W.W., and Greenhalgh, D.G. 1997. Apoptosis downregulates inflammation under the advancing epithelial wound edge: delayed patterns in diabetes and improvement with topical growth factors. Surgery. 121:372-380.

55. Ring, B.D., et al. 2000. Systemically and topically administered leptin both accelerate wound healing in diabetic ob/ob mice. Endocrinology. 141:446-449

56. Lord, G.M., et al. 1998. Leptin modulates the T-cell immune response and reverses starvation-induced immunosuppression. Nature. 394:897-901.

57. Howard, J.K., et al. 1999. Leptin protects mice from starvation-induced lymphoid atrophy and increases thymic cellularity in ob/ob mice. J. Clin. Invest. 104:1051-1059.

58. Barber, M., et al. 2003. Diabetes-induced neuroendocrine changes in rats: role of brain monoamines, insulin and leptin. Brain Res. 964:128-135. 